\title{
Experimental and Numerical Analysis of Vibrating Cracked Plates at Resonant Frequencies
}

\author{
by C.-C. Ma and C.-H. Huang
}

\begin{abstract}
Owing to the advantages of noncontact and fullfield measurement, an optical system called the amplitude fluctuation electronic speckle pattern interferometry (AFESPI) method with an out-of-plane setup is employed to investigate the vibration of a cantilever square plate with a crack emanating from one edge. Based on the fact that clear fringe patterns will be shown by the AFESPI method only at resonant frequencies, both the resonant frequencies and the vibration mode shapes can be obtained experimentally at the same time. Three different crack locations will be discussed in detail in this study. One is parallel to the clamped edge, and the other two are perpendicular to the clamped edge. The numerical finite element calculations are compared with the experimental results, and good agreement is obtained for resonant frequencies and mode shapes. The influences of crack locations and lengths on the vibration behavior of the clamped cantilever plate are studied in terms of the dimensionless frequency parameter $\left(\lambda^{2}\right)$ versus crack length ratio $(a / L)$. The authors find that if the crack face displacements are out of phase, a large value of stress intensity factor may be induced, and the cracked plate will be dangerous from the fracture mechanics point of view. However, there are some resonant frequencies for which the crack face displacements are completely in phase, causing a zero stress intensity factor, and the cracked plate will be safe.
\end{abstract}

KEY WORDS-AFESPI, resonant frequency, mode shape, crack, cantilever plate

Electronic speckle pattern interferometry (ESPI) was proposed in the $1970 \mathrm{~s}^{1}$ as a method of producing interferograms without using a traditional holographic technique. ${ }^{2}$ The main difference between ESPI and holography is the interferometric image processing. The image data are digitized by a video camera and digital signal processor for the ESPI method, which eliminates time-consuming chemical development. Because the interferometric image is recorded and updated by the video camera every $1 / 30 \mathrm{~s}$, ESPI is faster in operation and more insensitive to environmental noise than holography. Based on the reasons mentioned above, ESPI has become a powerful technique in many academic research and engineering applications.

C.-C. Ma is a Professor, Department of Mechanical Engineering, National Taiwan University, Taipei, Taiwan 106, Republic of China. C.-H. Huang is an Associate Professor, Department of Mechanical Engineering, Ching Yun Institute of Technology, Chung-Li, Taiwan 320, Republic of China.

Original manuscript submitted: October 6, 1999.

Final manuscript received: July 25, 2000.
The most widely used experimental setup to study vibration by ESPI is the time-averaged method. ${ }^{3}$ The disadvantage of this method is that the interferometric fringes represent only the amplitude but not the phase of the vibration. Løkberg and Hogmoen ${ }^{4}$ developed the phase modulation method that uses the reference beam modulation technique to determine the relative phase of the vibration object. For the purpose of reducing noise due to the environment, the subtraction method was developed. ${ }^{5,6}$ The difference of the subtraction method compared with the time-averaged method is that the reference frame is first recorded before vibration and continuously subtracted from the incoming frames after vibration.

To increase the visibility of the fringe pattern and reduce environmental noise simultaneously, an amplitude fluctua-

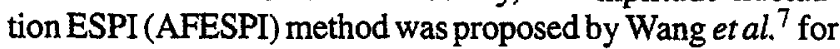
out-of-plane vibration measurement. In the AFESPI method, the reference frame is recorded in a vibrating state and subtracted from the incoming frame. Consequently, it combines the advantages of the time-averaged and subtraction methods, i.e., good visibility and noise reduction. $\mathrm{Ma}$ and Huang 8,9 used the AFESPI method to investigate the three-dimensional vibrations of piezoelectric rectangular parallelepipeds and cylinders. Both the resonant frequencies and mode shapes were presented and discussed in detail.

In the field of plate vibrations, a great amount of research and literature has been presented over the past century. ${ }^{10} \mathrm{Be}$ cause the rectangular cantilever plate is one of the most commonly used types, its dynamic behavior is of importance to the design engineer. The study of the vibration behavior of a plate with a crack is a problem of great practical interest. Only a few papers have been published on the vibration analysis of a finite cracked plate. This problem combines the fields of vibration analysis and fracture mechanics. The presence of cracks will affect the static and dynamic characteristics of the plate, such as static deflection and natural frequency. This behavior should be attributed to the ways in which cracks will alter the local stiffness of the plate. Nevertheless, compared with studies in the past, there is little research on the influence of cracks on the vibration behavior of plates.

Vibrations of a cracked rectangular plate were investigated by Lynn and Kumbasar, ${ }^{11}$ who used Green's function to represent the deflections of plates and to obtain a homogeneous Fredholm integral equation of the first kind. Stahl and $\mathrm{Keer}^{12}$ studied the vibration and stability of cracked rectangular plates in terms of dual-series equations, which were then converted to a homogeneous Fredholm integral equation of the second kind. However, in these studies, the crack was limited to a position along the symmetry axis of the plate. Hirano and OKazaki ${ }^{13}$ studied a rectangular plate with cracks 
perpendicular to the simply supported edges. Levy-Nadai's form of solution was used, and the discontinuity of deflection and slope of the cracks on both sides were expanded into Fourier series along the line involving the cracks. Solecki ${ }^{14}$ applied similar concepts to the discontinuous conditions in terms of finite Fourier transformation. For more complex structures, application of finite element methods comes naturally. Qian et al. ${ }^{15}$ presented a finite element method using an element stiffness matrix that was derived from the integration of the stress intensity factor. Experiments by spectrum analysis were investigated and compared with the numerical computations. The method mentioned above is similar to the method proposed by Krawczuk, ${ }^{16}$ but the stiffness matrix was presented in a closed form. Lee and $\mathrm{Lim}^{17}$ investigated the vibration of a central-cracked plate based on the Rayleigh method. The effects of transverse shear deformation and rotary inertia were included in the numerical calculation in that study.

In the aspect of experimental studies, Maruyama and Ichinomiya ${ }^{18}$ used time-averaged holographic interferometry to investigate the natural frequencies and corresponding mode shapes experimentally with regard to the influence of the slit length, position and inclination angle of clamped rectangular plates. The determination of the location of defects in plates from measurements of natural frequencies of cracked plates was studied by Cawley and Adams. ${ }^{19}$

Measurement of natural frequencies is potentially a very attractive method of nondestructive test, since only one test is required to assess the integrity of the complete component. This removes the need for the time-consuming scanning of a probe over all the areas such as in conventional ultrasonic inspection. To determine whether this technique can be used to detect defects of the crack size in a beam, the vibration behavior of cantilevered beams with edge cracks was investigated by Gudmundson. ${ }^{20}$ The crack closure effect was experimentally investigated with a fatigue crack, and it was found that this effect was of considerable importance for a vibrating beam with cracks. Cawley and Ray ${ }^{21}$ investigated the changes in the natural frequencies of a beam produced by cracks, which were compared with changes in the natural frequencies caused by slots of the same depth and different widths.

In this paper, we employ the optical method based on the AFESPI method to study the resonant properties of square cantilever plates with cracks. The advantage of using the AFESPI method is that resonant frequencies and the corresponding mode shapes can be obtained simultaneously. This aids the investigation of the influence of crack location and crack length on vibration behavior. Cracks that are parallel to and perpendicular to the clamped edge are chosen for investigation. The cracks are modeled by sawing cuts in the specimens. In addition to the AFESPI method, numerical computations based on a finite element package are presented, and good agreement is found in comparison with experimental results. Furthermore, crack face displacements and crackopening displacements are calculated to study the fracture problem induced by the resonant vibration. It is interesting to discover that at some resonant frequencies, the crack face displacements are completely in phase, which yields a zero stress intensity factor, and crack propagation will not occur.

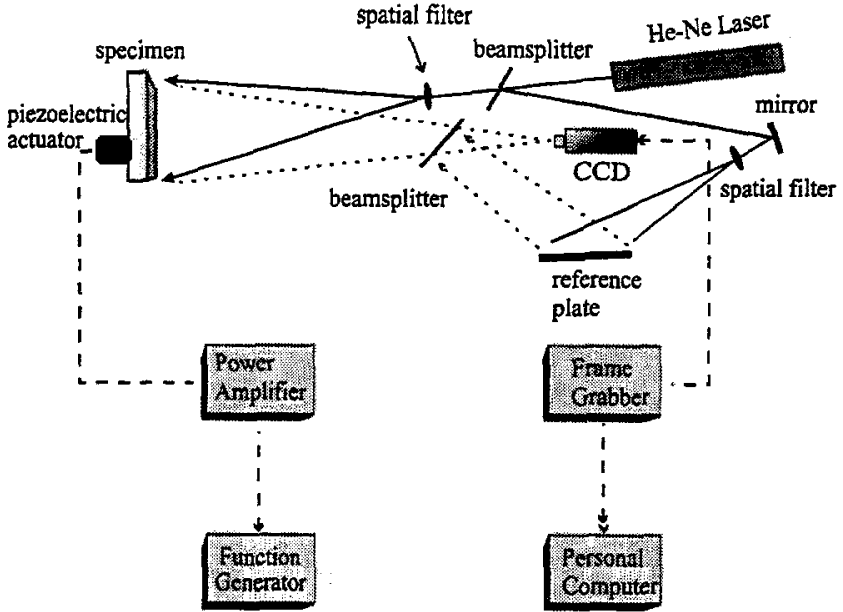

Fig. 1-Schematic diagram of electronic speckle pattern interferometry experimental setup for out-of-plane measurement

\section{Theory of the AFESPI Method for Out-of-plane Vibration Measurement}

The optical arrangement for out-of-plane vibrating measurement by ESPI is shown schematically in Fig. 1. If the image of the specimen is taken at the stress-free state, the light intensity detected by a CCD camera can be expressed by the time-averaged method as

$$
\begin{aligned}
I_{0} & =\frac{1}{\tau} \int_{0}^{\tau}\left(I_{A}+I_{B}+2 \sqrt{I_{A} I_{B}} \cos \phi\right) d t \\
& =I_{A}+I_{B}+2 \sqrt{I_{A} I_{B}} \cos \phi,
\end{aligned}
$$

where $I_{A}$ is the object light intensity, $I_{B}$ is the reference light intensity, $\tau$ is the CCD refreshing time and $\phi$ is the phase difference between object and reference light.

Assuming the specimen vibrates periodically, the light intensity taken by a CCD camera can be represented as

$$
\begin{aligned}
I_{1}= & \frac{1}{\tau} \int_{0}^{\tau}\left\{I_{A}+I_{B}+2 \sqrt{I_{A} I_{B}} \cos \right. \\
& {\left.\left[\phi+\frac{2 \pi}{\lambda}(1+\cos \theta) A \cos \omega t\right]\right\} d t, }
\end{aligned}
$$

where $\lambda$ is the wavelength of laser, $\theta$ is the angle between object light and observation direction, $A$ is the vibration amplitude and $\omega$ is the angular frequency.

Let $\Gamma=\frac{2 \pi}{\lambda}(1+\cos \theta)$ and assume $\tau=\frac{2 m \pi}{\omega}$, where $m$ is an integer, and eq (2) can be expressed as

$$
I_{1}=I_{A}+I_{B}+2 \sqrt{I_{A} I_{B}}(\cos \phi) J_{0}(\Gamma A),
$$

where $J_{0}$ is a zero-order Bessel function of the first kind.

When these two images $\left(I_{0}\right.$ and $\left.I_{1}\right)$ are subtracted and rectified by the image-processing system, i.e., subtract eq (1) from eq (3), the resulting image intensity can be expressed as

$$
I=I_{1}-I_{0}=2 \sqrt{I_{A} I_{B}}\left|(\cos \phi)\left[J_{0}(\Gamma A)-1\right]\right| .
$$


The light intensity of the image shown in eq (4) is called the subtraction method, and the reference image is recorded before loading is applied.

Instead of using the subtraction method, the AFESPI method is employed in this study by taking two images while the specimen vibrates and assuming that the vibration amplitude of the second image has changed from $A$ to $A+\Delta A$ due to the instability of the apparatus. The light intensity of the second image will be

$$
\begin{aligned}
I_{2}= & \frac{1}{\tau} \int_{0}^{\tau}\left\{I_{A}+I_{B}+2 \sqrt{I_{A} I_{B}} \cos \right. \\
& {[\phi+\Gamma(A+\Delta A) \cos \omega t]\} d t . }
\end{aligned}
$$

Expand eq (5) by using Taylor series and neglect higher order terms to obtain

$$
\begin{aligned}
I_{2}= & I_{A}+I_{B}+2 \sqrt{I_{A} I_{B}}(\cos \phi) \\
& {\left[1-\frac{1}{4} \Gamma^{2}(\Delta A)^{2}\right] J_{0}(\Gamma A) . }
\end{aligned}
$$

When these two images $\left(I_{1}\right.$ and $\left.I_{2}\right)$ are subtracted and rectified by the image-processing system, i.e., subtract eq (3) from eq (6), the resulting image intensity can be expressed as

$$
I=I_{2}-I_{1}=\frac{\sqrt{I_{A} I_{B}}}{2}\left|(\cos \phi) \Gamma^{2}(\Delta A)^{2} J_{0}(\Gamma A)\right| .
$$

Compared with the subtraction method, where the reference image is taken at the stress-free state, the reference image is recorded and subtracted at the vibrating state by the AFESPI method. From eq (4) and eq (7), the dominant function of the AFESPI method is $\left|J_{0}(\Gamma A)\right|$ and that of the subtraction method is $\left|J_{0}(\Gamma A)-1\right|$. Owing to the discrepancy between the dominant functions, the nodal lines of vibrating interferometric patterns obtained by the AFESPI method are the bright fringes and those obtained by the subtraction method are the dark fringes. This characteristic of AFESPI can be used for qualitative observation or for quantitative analysis for the fringe patterns. Furthermore, the sensitivity and fringe visibility of the AFESPI method are better than those of the subtraction method. It can be verified that, compared with the subtraction method, the number of fringes presented by the AFESPI method is about twice as much (under the assumption of same vibration amplitude). In addition to the theory of out-of-plane measurement mentioned above, the in-plane vibration measurement by the AFESPI method can be derived in a similar way. ${ }^{8}$

\section{Experimental Result and Numerical Analysis}

An aluminum square plate (6061T6) with a straight crack is used in this study for vibration analysis. The material properties of the plate are mass density $\rho=2700 \mathrm{~kg} / \mathrm{m}^{3}$, Young's modulus $E=70 \mathrm{GPa}$ and Poisson's ratio $\nu=0.33$. Three plates with different locations of the crack are discussed in the present study, which include two vertical cracks (VC1 and VC2) and one horizontal crack (HC). The locations of cracks and the geometric dimension of the square plate are illustrated in Fig. 2 . The cracks are modeled by sawing cuts with a width of $0.2 \mathrm{~mm}$. The crack length $a$ is taken to be $1 \mathrm{~cm}$,

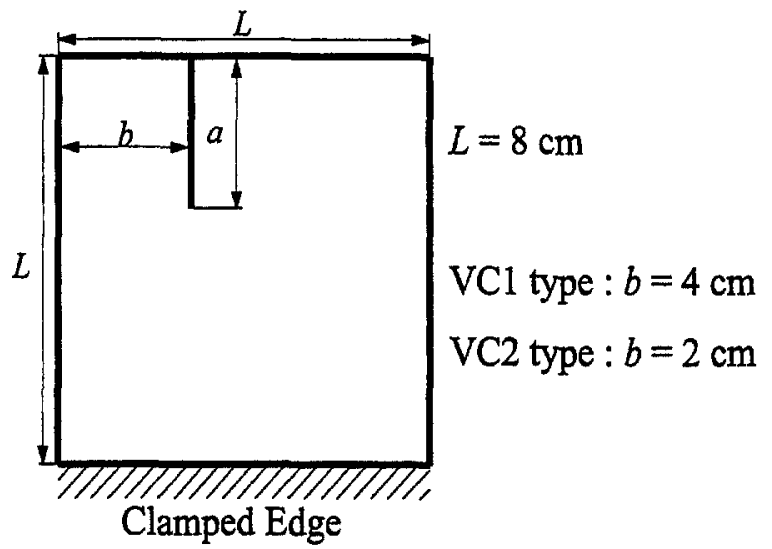

(a)

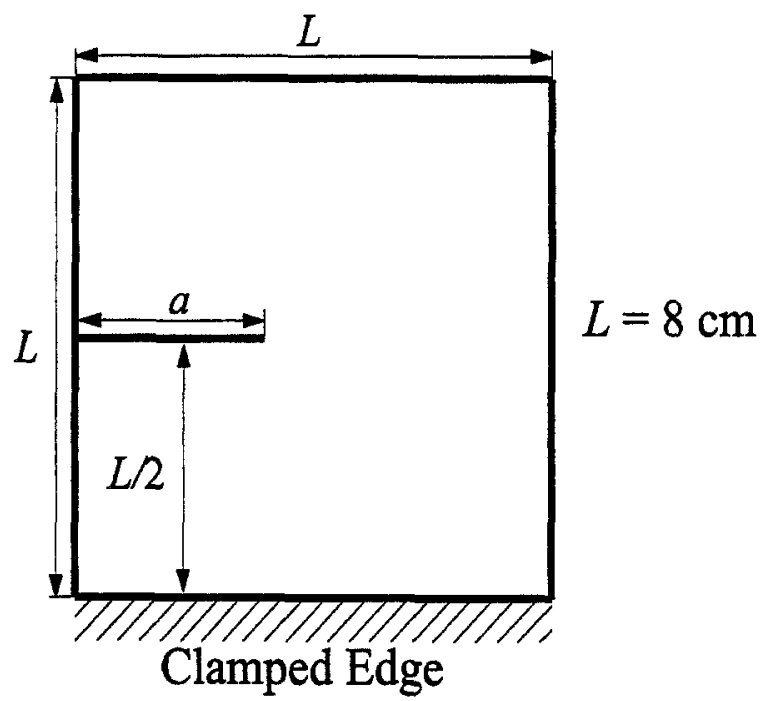

(b)

Fig. 2-Geometric dimensions and configurations of (a) VC1, $\mathrm{VC2}$ and (b) HC plates

$2 \mathrm{~cm}, 3 \mathrm{~cm}, 4 \mathrm{~cm}$ and $5 \mathrm{~cm}$ for three locations of cracks. For convenience, we note that VC1-2 represents the crack type VC1 with crack length $2 \mathrm{~cm}$. To increase the contrast of fringe patterns, the surfaces of these plates were coated with white paint mixed with fine powder.

The resonant frequencies and mode shapes can be determined from this experimental setup at the same time. An He-Ne laser with $30 \mathrm{~mW}$ and wavelength $\lambda=632.8 \mathrm{~nm}$ is used as the coherent light source. The laser beam is divided into two parts, the reference beam and object beam, by a beam splitter. The object beam travels to the specimen and then reflects to the CCD camera. The reference beam goes directly to the CCD camera via a mirror and a reference plate. Note that the optical path length and the light intensities of these two beams should remain identical in the experimental setup. The plate is excited to resonance by a $5 \mathrm{~mm}$ $\times 5 \mathrm{~mm} \times 10 \mathrm{~mm}$ piezostack actuator (Physik Instrumente) that is attached behind the specimen. The piezoelectric actuator is usually attached in the center of the opposite face of the cracked plate. However, if the nodal lines or crack faces pass the center of the specimen, the piezoelectric actuator is moved to other locations. To achieve the sinusoidal output, a digitally controlled function generator HP33120A (Hewlett 
Packard) connected to a 4005 power amplifier (Electron Instruments) is used.

Numerical results of resonant frequencies and mode shapes are calculated by the ABAQUS finite element package $^{22}$ in which eight-node two-dimensional shell elements (S8R5) are selected. The finite element mesh in the vicinity of the crack tip is divided because of stress concentration at the crack tip. By placing the first node away from that point at one-quarter of the distance to the second point (hence, the "quarter point" method), the stress near the crack tip will behave as a square root singularity.

Table 1 shows the experimental and numerical results of resonant frequencies of the first seven modes for crack lengths $2 \mathrm{~cm}$ and $5 \mathrm{~cm}$ of $\mathrm{VCl}, \mathrm{VC} 2$ and $\mathrm{HC}$ cracked plates. The results are quite consistent. All the experimental measured frequencies are lower than the numerical frequencies. The main reason is believed to be that the clamped condition of the cantilever cracked plate for the experimental setup is not ideally rigid.

The contours of resonant mode shapes in the finite element calculation are plotted for comparison with the experimental observation. Only experimental results of the mode shapes for a long crack (crack length $=5 \mathrm{~cm}$ ) are presented here due to space limitations. Figures 3-5 show the first seven mode shapes for both experimental measurements and numerical simulations. In these figures, we indicate the phase of displacement in finite element results as + or - . The regions of the same sign have in-phase motion, and nodal lines are located between + and - regions. The brightest fringes represent the nodal lines of the vibrating cracked plate at resonant frequencies. The rest of the fringes are contours of constant displacement. The experimental and numerical results agree well for both the resonant frequencies and the mode shapes.

To discuss the influences of the crack length and crack location on the resonant frequencies, the resonant frequency $f$ is expressed by means of a dimensionless frequency parameter $\lambda^{2}$ given by

$$
\lambda^{2}=2 \pi f L^{2} \sqrt{\frac{12 \rho\left(1-\nu^{2}\right)}{E h^{2}}},
$$

where $L$ is the length and $h$ is the thickness of the square plate.

Figure 6 shows the dependence of resonant frequency $\left(\lambda^{2}\right)$ on nondimensional crack length $(a / L)$ for three cracked plates. In most cases, the frequencies vary inversely as the crack length increases. This phenomenon can be expected because the rigidity of the cracked plate decreases as the crack length increases. Generally, the dependence of resonant frequencies on crack length for lower modes is not as great compared with higher modes. For VC1 and HC cases, the frequencies of mode 6 decrease violently for $a / L>0.2$; on the contrary, mode 7 decreases only slightly for $a / L>0.2$. For the VC2 plate, the frequencies of mode 6 and mode 7 both decrease in a similar way. The influence of crack location on the resonant frequencies for different crack lengths is shown in Fig. 7. For mode 1, the frequencies decrease as the crack length increases for HC type and remain constant for $\mathrm{VC} 1$ and $\mathrm{VC} 2$. It is interesting to note that for the cantilever cracked plate, the resonant frequency of the first mode is independent of the crack length for the crack that is perpendicular to the clamped edge. We also can see from Figs. 3 and 4 that the mode shapes for the first mode of plates VC1 and
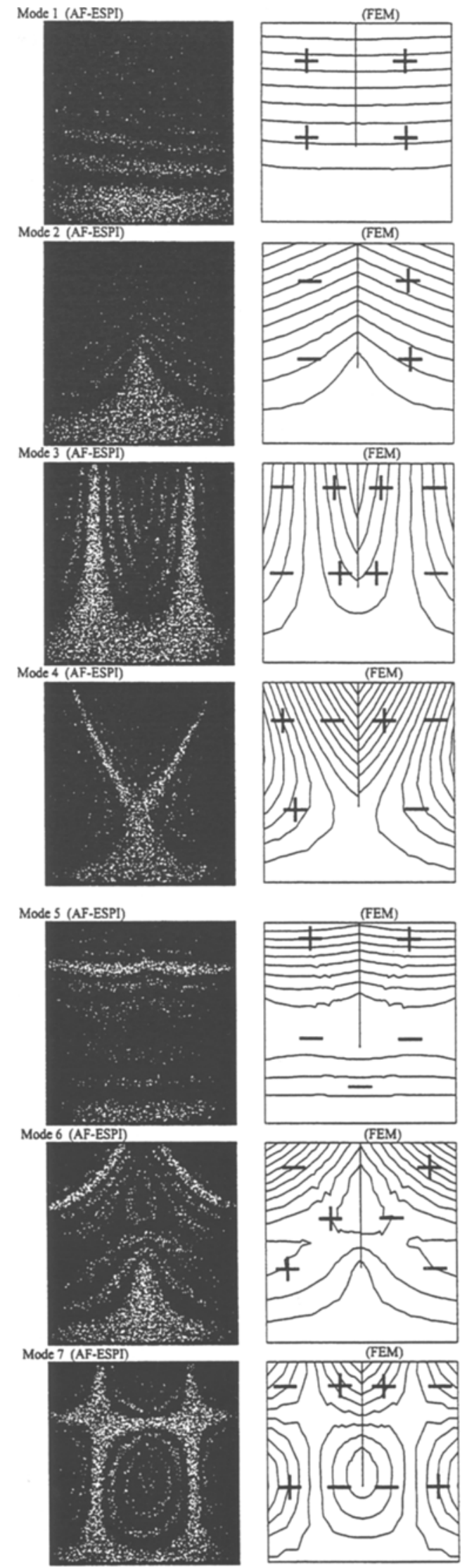

Fig. 3-Mode shapes of the VC1-5 plate obtained by amplitude fluctuation electronic speckle pattern interferometry (AFESPI) and the finite element method (FEM) 
TABLE 1-RESULTS OF THE FIRST SEVEN RESONANT FREQUENCIES OBTAINED FROM AMPLITUDE FLUCTUATION ELECTRONIC SPECKLE PATTERN INTERFEROMETRY AND THE FINITE ELEMENT METHOD FOR (A) VC1, (B) VC2 AND (C) HC PLATES WITH CRACK LENGTHS OF $2 \mathrm{~cm}$ AND $5 \mathrm{~cm}$

\begin{tabular}{|c|c|c|c|c|}
\hline & \multicolumn{2}{|c|}{ VC1 $(2 \mathrm{~cm})$} & \multicolumn{2}{|c|}{$\operatorname{VC1}(5 \mathrm{~cm})$} \\
\hline & AFESPI (Hz) & FEM $(\mathrm{Hz})$ & AFESPI (Hz) & FEM $(\mathrm{Hz})$ \\
\hline \multirow[t]{3}{*}{$\begin{array}{l}\text { Mode } 1 \\
\text { Mode } 2 \\
\text { Mode } 3 \\
\text { Mode } 4 \\
\text { Mode } 5 \\
\text { Mode } 6 \\
\text { Mode } 7 \\
\end{array}$} & $\begin{array}{r}129 \\
294 \\
753 \\
883 \\
965 \\
1738 \\
1935 \\
\end{array}$ & $\begin{array}{r}134 \\
302 \\
794 \\
914 \\
1001 \\
1829 \\
2018 \\
\end{array}$ & $\begin{array}{r}128 \\
180 \\
585 \\
635 \\
788 \\
1101 \\
1880 \\
\end{array}$ & $\begin{array}{r}134 \\
186 \\
607 \\
661 \\
829 \\
1141 \\
1940 \\
\end{array}$ \\
\hline & \multicolumn{2}{|c|}{ VC2 $(2 \mathrm{~cm})$} & \multicolumn{2}{|c|}{$\mathrm{VC2}(5 \mathrm{~cm})$} \\
\hline & AFESPI $(\mathrm{Hz})$ & FEM (Hz) & AFESPI $(\mathrm{Hz})$ & FEM $(\mathrm{Hz})$ \\
\hline \multirow[t]{3}{*}{$\begin{array}{l}\text { Mode 1 } \\
\text { Mode } 2 \\
\text { Mode } 3 \\
\text { Mode } 4 \\
\text { Mode } 5 \\
\text { Mode } 6 \\
\text { Mode } 7 \\
\end{array}$} & $\begin{array}{r}130 \\
297 \\
773 \\
855 \\
1062 \\
1645 \\
1979 \\
\end{array}$ & $\begin{array}{r}134 \\
309 \\
798 \\
901 \\
1100 \\
1713 \\
2085 \\
\end{array}$ & $\begin{array}{r}129 \\
193 \\
448 \\
798 \\
965 \\
1287 \\
1565 \\
\end{array}$ & $\begin{array}{r}134 \\
199 \\
463 \\
825 \\
984 \\
1322 \\
1637 \\
\end{array}$ \\
\hline & \multicolumn{2}{|c|}{$H C(2 \mathrm{~cm})$} & \multicolumn{2}{|c|}{$\mathrm{HC}(5 \mathrm{~cm})$} \\
\hline & AFESPI $(\mathrm{Hz})$ & FEM $(\mathrm{Hz})$ & AFESPI $(\mathrm{Hz})$ & FEM $(\mathrm{Hz})$ \\
\hline $\begin{array}{l}\text { Mode } 1 \\
\text { Mode } 2 \\
\text { Mode } 3 \\
\text { Mode } 4 \\
\text { Mode } 5 \\
\text { Mode } 6 \\
\text { Mode } 7 \\
\end{array}$ & $\begin{array}{r}123 \\
284 \\
704 \\
942 \\
1061 \\
1633 \\
1992 \\
\end{array}$ & $\begin{array}{r}130 \\
296 \\
739 \\
983 \\
1114 \\
1679 \\
2111 \\
\end{array}$ & $\begin{array}{r}100 \\
189 \\
530 \\
727 \\
986 \\
1051 \\
1778 \\
\end{array}$ & $\begin{array}{r}102 \\
197 \\
552 \\
754 \\
1011 \\
1113 \\
1865 \\
\end{array}$ \\
\hline
\end{tabular}

$\mathrm{VC}=$ vertical crack, $\mathrm{HC}=$ horizontal crack, AFESPI = amplitude fluctuation electronic speckle pattern interferometry,

$\mathrm{FEM}=$ finite element method

VC2 are almost the same as those for the cantilever plate with no crack. Hence, the existence of vertical cracks (VC1 and VC2) do not affect the resonant frequency of the first mode. For mode 2 , the dependence of frequencies on crack length is very similar for three types of cracked plate. The nodal line coincides with the crack and terminates at the crack tip for VCl as shown in Fig. 3. For both modes 3 and 4, mode shapes (see Figs. 3-5) for long cracks are quite different compared with the case of a short crack for all three plates. The resonant frequency of mode 5 for the VC1 plate decreases rapidly with increased crack length because of the change of mode shapes (see Fig. 3). The mode shape is anti-symmetric for short cracks but symmetric (in phase) for long cracks. The variation of resonant frequency for different crack lengths of mode 6 is the greatest in all cases. This implies that resonant frequency for mode 6 is very sensitive to the crack length. Note that for mode 7 , the decreasing tendency of resonant frequencies for the VC2 plate is different from that for VC1 and $\mathrm{HC}$ plates. The mode shapes of mode 7 for $\mathrm{VCl}$ and $\mathrm{HC}$ plates are similarly maintained for short and long cracks.

Finally, the crack face displacement and the crack-opening displacement for different resonant frequencies of three cracked plates are investigated, and the results are shown in Figs. 8-13. In these figures, the out-of-plane displacement $w$ and the crack-opening displacement along the crack face are normalized with $w_{\max }$, which is the maximum displacement in the whole plate. The distance from the crack face to the crack tip is denoted as $x$ and is normalized with the crack length $a$. From the fracture mechanics point of view, the out-of-plane displacement will induce a mode III (anti-plane mode) type of fracture. A large crack-opening displacement will induce a large stress intensity factor, which will initiate crack propagation, and the cracked plate will be dangerous. Figure 8(a) shows crack face displacements of the VC1-2 plate for seven modes. There are four modes (modes 1, 3, 4 and 7) for which the displacement of the two crack faces is in phase, and three modes (modes 2, 5 and 6) for which the displacement is out of phase. Figure 8 (b) shows the crackopening displacement (i.e., the difference of the displacement between upper and lower crack faces) for the VC1-2 plate. If the crack face displacement is in phase, one finds that the crack-opening displacement will be zero. The crack-opening displacement varies almost linearly along the crack face for the case of out-of-phase motion. The results for a long crack, i.e., the VC1-5 plate, are shown in Figs. 9(a) and 9(b). There are four modes (modes 1,3,5 and 7) that are in phase and three modes (modes 2, 4 and 6) that are out of phase, and the crack-opening displacement is zero for the case of in phase. It is also indicated that if the displacement is zero at some points in the crack face, i.e., modes 5 and 7 in Fig. 9(a) for the VC1-5 plate, then the nodal line will pass that point. The experimental result of the crack face displacement for the VC1 plate is shown in Fig. 3. It is worth noting that if the displacement of the crack face is out of phase, the crack tip is always located in the nodal line. It is concluded that the crack-opening displacement is zero when the displacement of the crack faces is in phase (i.e., modes 1, 3, 4 and 7 for the VC1-2 plate and modes $1,3,5$ and 7 for the VCl-5 plate); 

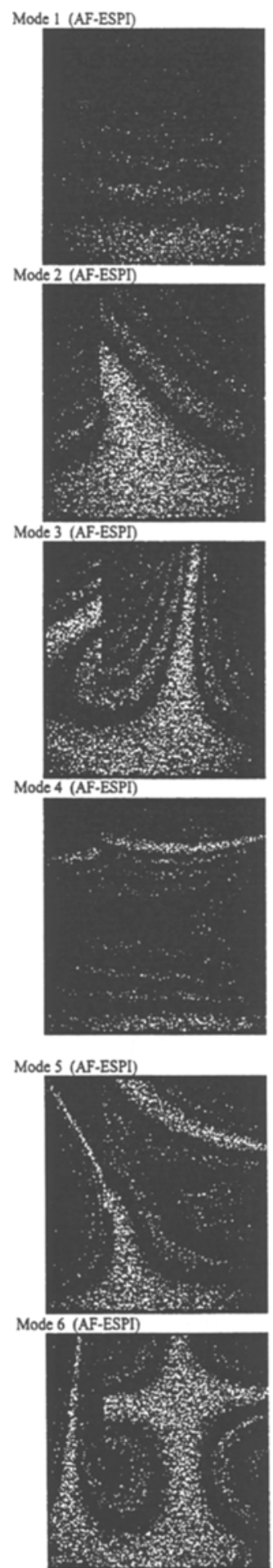

Mode 7 (AF-ESPD)
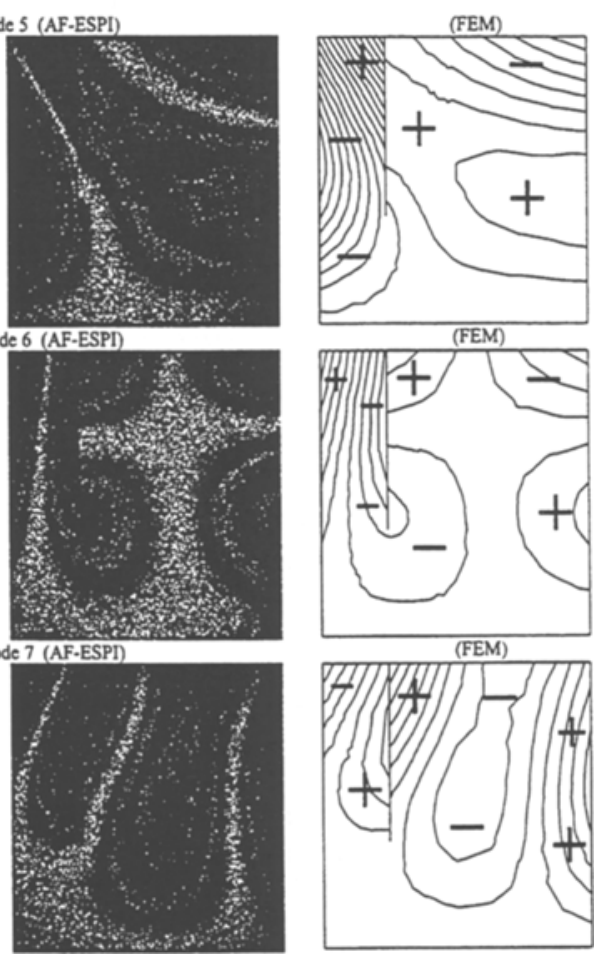

Fig. 4-Mode shapes of the VC2-5 plate obtained by amplitude fluctuation electronic speckle pattern interferometry (AFESPI) and the finite element method (FEM)
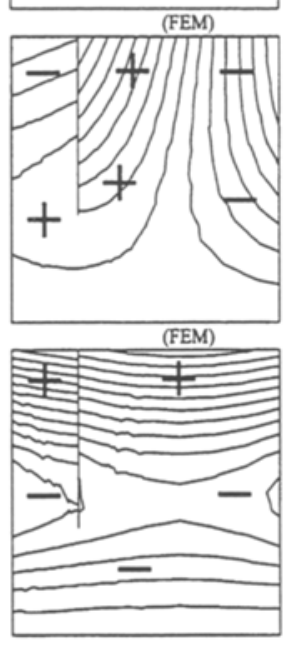
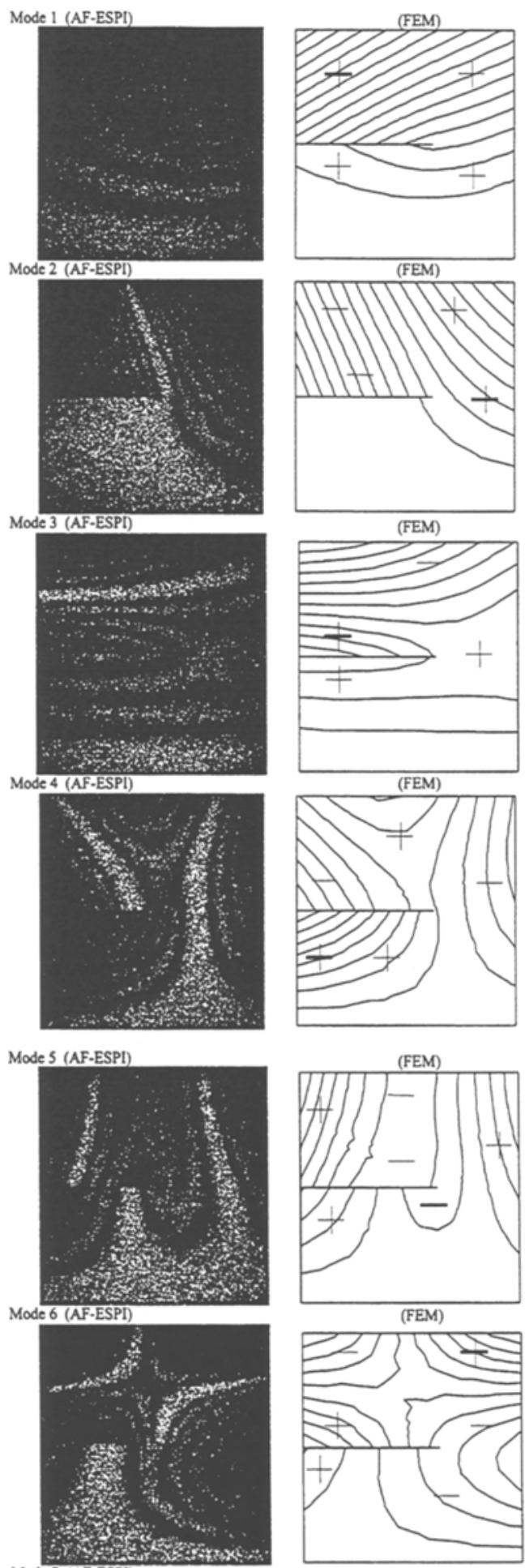

Mode 7 (AF-ESPI)
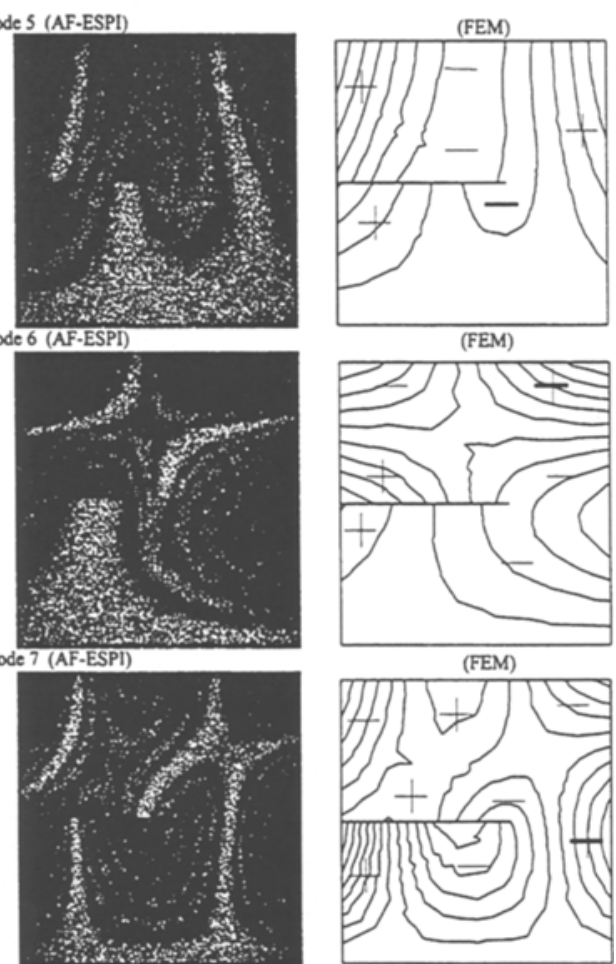

Fig. 5-Mode shapes of the HC-5 plate obtained by amplitude fluctuation electronic speckle pattern interferometry (AFESPI) and the finite element method (FEM) 


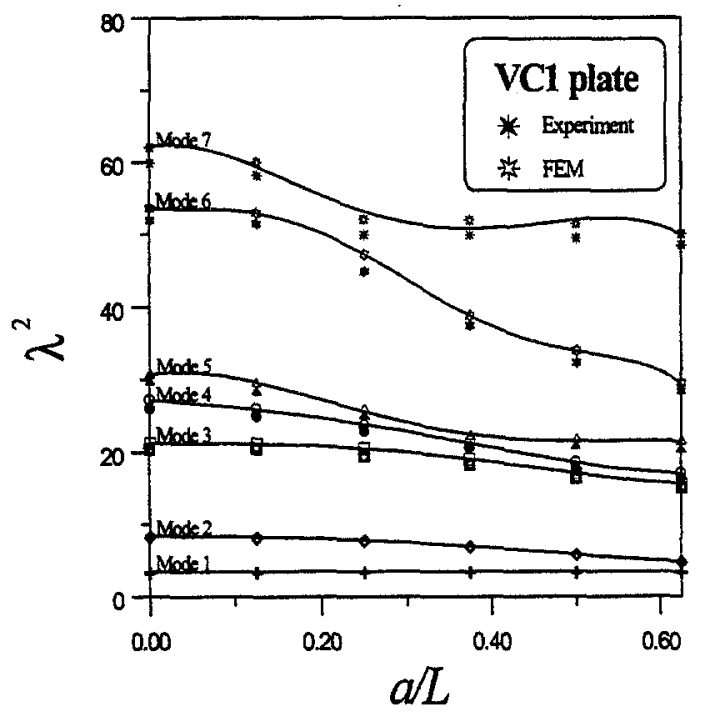

(a)

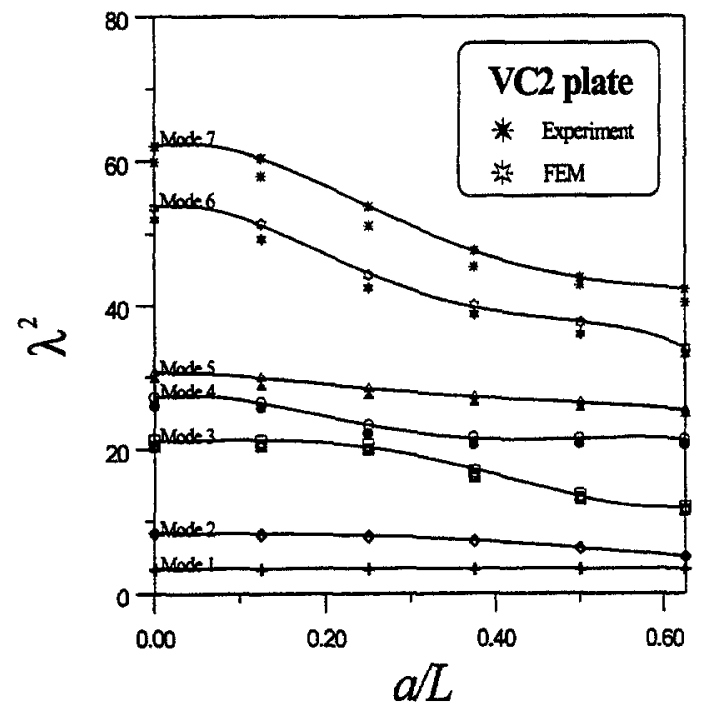

(b)

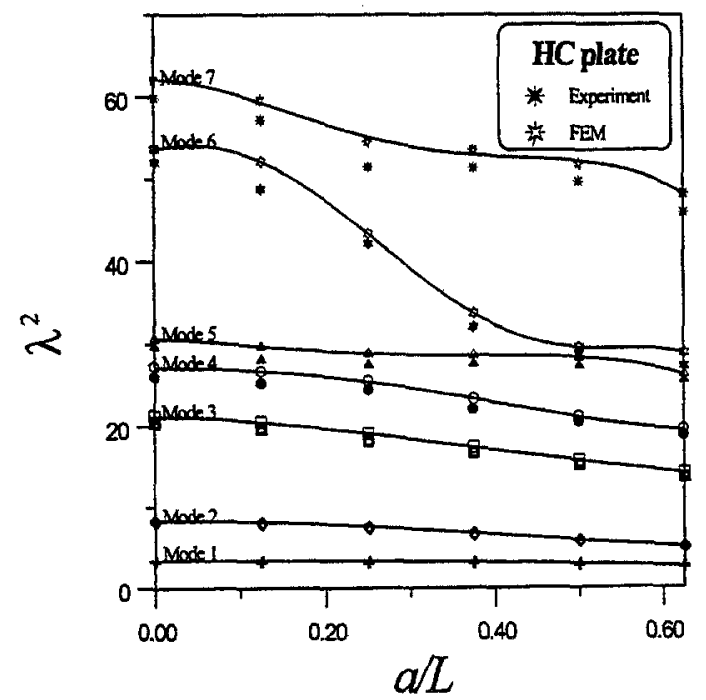

(c)

Fig. 6-Results of resonant frequencies obtained from amplitude fluctuation electronic speckle pattern interferometry and the finite element method (FEM) for (a) VC1, (b) VC2 and (c) $\mathrm{HC}$ plates

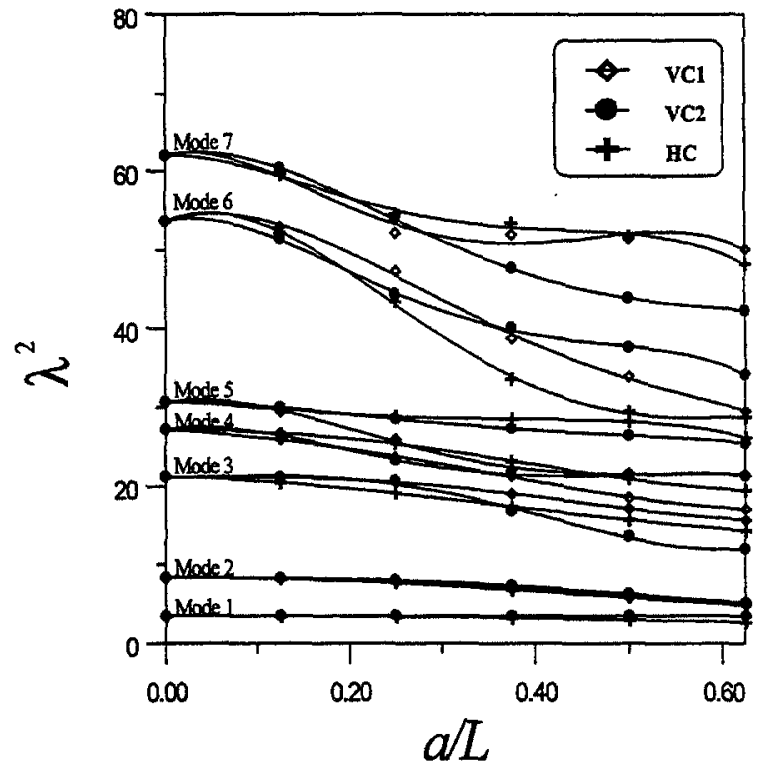

Fig. 7-Comparison of resonant frequencies of the VC1, $\mathrm{VC} 2$ and $\mathrm{HC}$ plates for the first seven modes

hence, the stress intensity factor is zero, which implies that the crack is safe in these resonant frequencies for the VC1 plate.

The crack face displacements for the VC2-2 plate are shown in Fig. 10(a). There are five modes (modes 1, 2, 3, 5 and 7) that are in phase and two modes (modes 4 and 6) that are out of phase. The crack face displacements of some modes (modes 2, 3,5 and 7) are in phase, but the magnitudes of the displacements are different in upper and lower crack faces; hence, the crack-opening displacement for these cases is not zero [the result is shown in Fig. 10(b)]. From the fracture mechanics point of view, the most dangerous case for the VC2-2 plate is mode 6, since it has the largest value of crackopening displacement. The crack face displacements and the crack-opening displacements for the VC2-5 plate are shown in Figs. 11(a) and 11(b), respectively. Note that the crack faces cross each other for modes 5 and 7 at $x / a=0.41$ and $x / a=0.6$, respectively. The dangerous cases for the VC2-5 plate are modes 2, 3 and 7 . It is found that the crack-opening displacement of mode 1 for both VC2-2 [see Fig. 10(b)] and VC2-5 [Fig. 11(b)] plates is zero along the crack face; hence, the stress intensity factor is zero for the VC2 plate.

The crack face displacements and the crack-opening displacements for the HC-2 plate are shown in Figs. 12(a) and 12(b), respectively. Only modes 4 and 6 are out of phase, and the crack-opening displacement for mode 1 is very small. The most dangerous case for the HC-2 plate is mode 6 . The crack face displacements and the crack-opening displacements for the HC-5 plate are shown in Figs. 13(a) and 13(b), respectively. The crack faces for mode 7 cross each other, and mode 4 has the largest crack-opening displacement along the crack faces.

Because the crack will introduce a new free boundary of the cantilever plate, the mode shape of a cracked plate is complicated and quite different from that of a plate without a crack. The resonant frequencies and mode shapes of the 


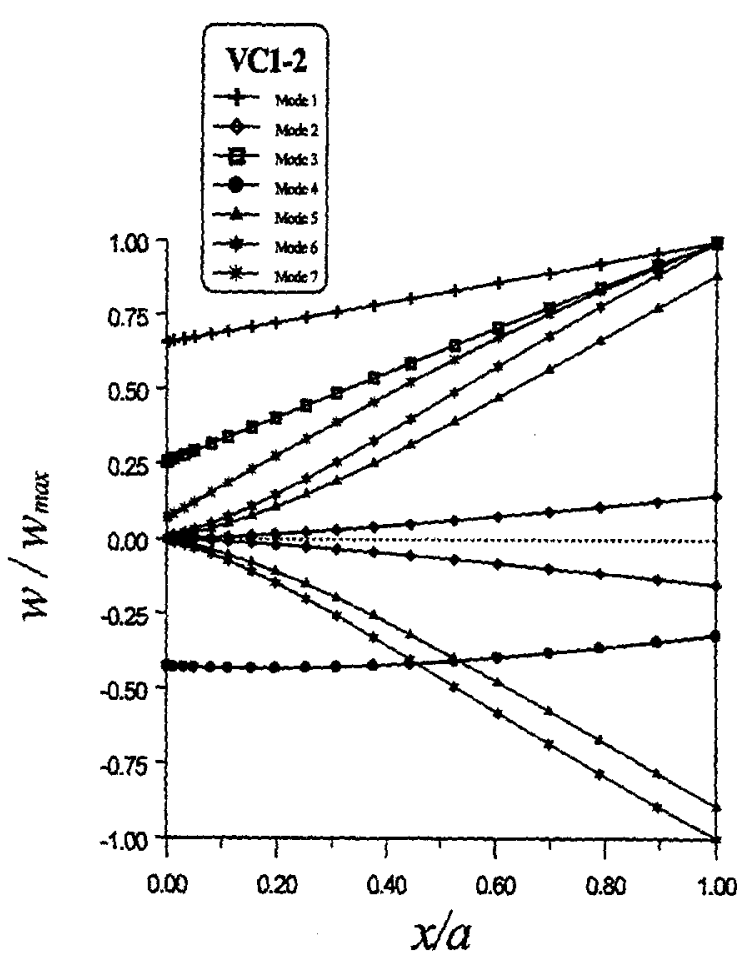

(a)

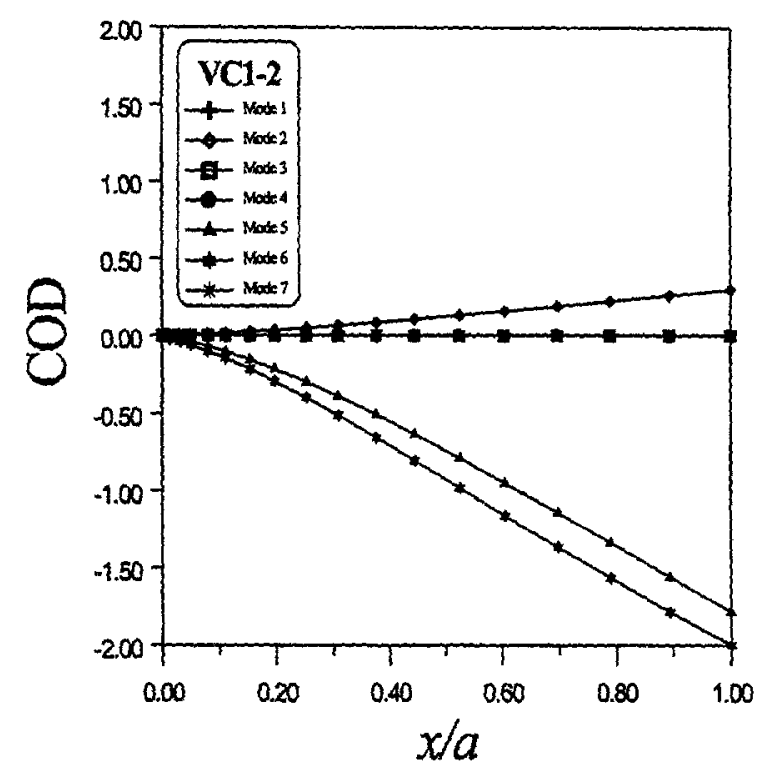

(b)

Fig. 8-(a) Normalized displacement $\left(w / w_{\max }\right)$ and (b) crackopening displacement (COD) values of the crack faces for the VC1-2 plate

first mode for VC1 and VC2 plates are exactly the same as those of the uncracked plate. Furthermore, the crack-opening displacement of the crack is zero, and the cracked plate is safe in the first resonant mode from the fracture mechanics point of view. If the crack is perpendicular to the fixed boundary of the cantilever plate, the existence of the crack has no influence on the resonant frequency and the mode shape of the cantilever cracked plate. In general, the cantilever cracked plate will be dangerous at a resonant frequency for which the crack face displacement is out of phase; it is less dangerous when the crack face displacement is in phase.

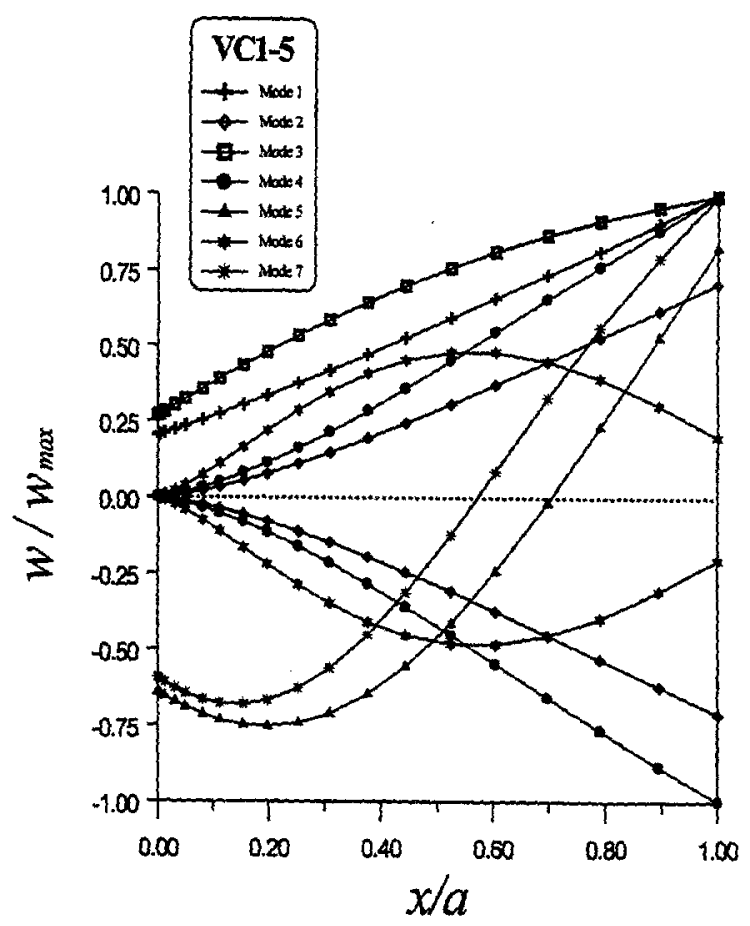

(a)

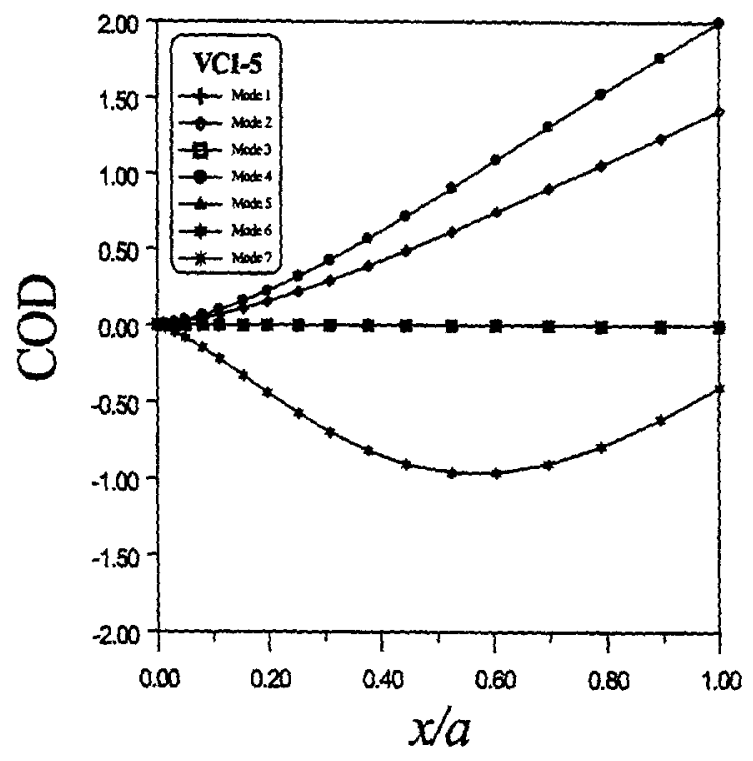

(b)

Fig. 9-(a) Normalized displacement ( $w / w_{\max }$ ) and (b) crackopening displacement (COD) values of the crack faces for the VC1-5 plate

\section{Conclusions}

Investigation of the vibration problem by employing the ESPI method has the advantages of real-time and noncontact measurement, submicron sensitivity, digital image processing and so on. In this paper, the AFESPI optical setup with good fringe visibility and noise reduction was established to obtain the resonant frequencies and corresponding mode shapes of cantilever cracked plates at the same time. Compared with the spectrum analysis method or modal analysis method, AFESPI is more convenient in experimental measurement. Numerical calculations of resonant frequencies 


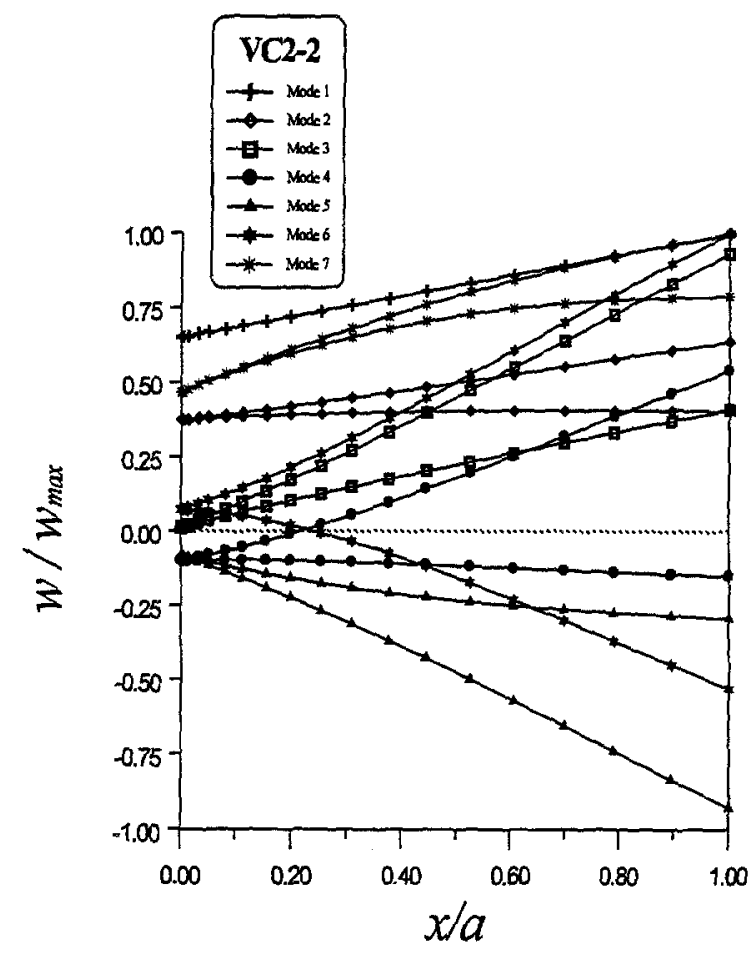

(a)

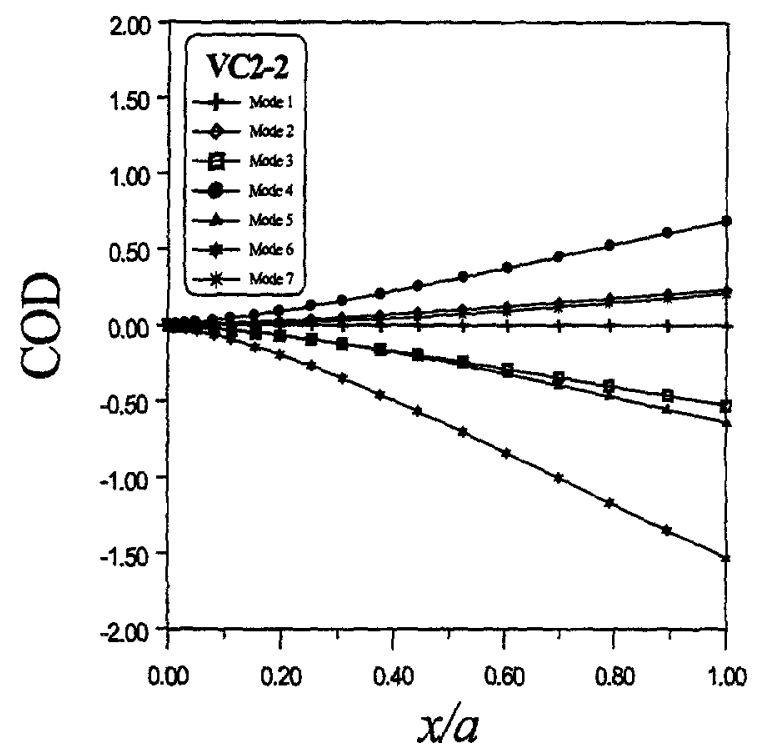

(b)

Fig. 10-(a) Normalized displacement $\left(w / w_{\max }\right)$ and (b) crack-opening displacement (COD) values of the crack faces for the VC2-2 plate

and mode shapes based on a finite element package are also performed in this study, and good agreements are obtained in comparison with experimental measurements. The influence of the crack location and crack length on the vibration behavior of the cantilever cracked plate is discussed in detail. It is found that if the crack is perpendicular to the fixed boundary, the resonant frequency and mode shape are exactly the same as that of a cantilever plate with no crack. The displacement and crack-opening displacement along the crack face were also investigated. The displacements at some modes are found to be completely in phase, which makes zero crack-

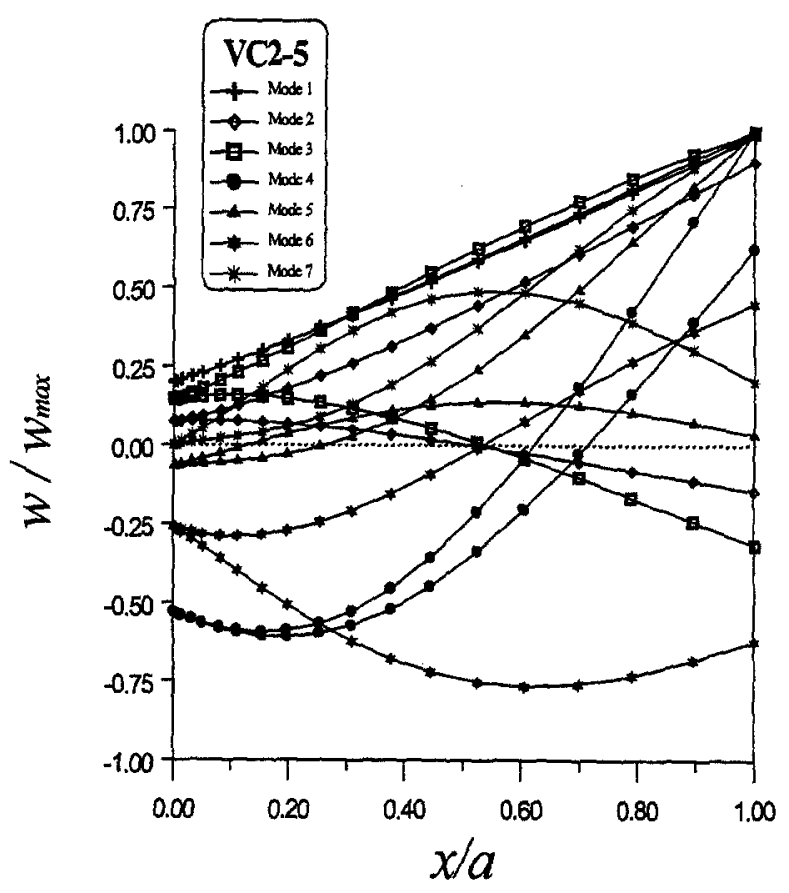

(a)

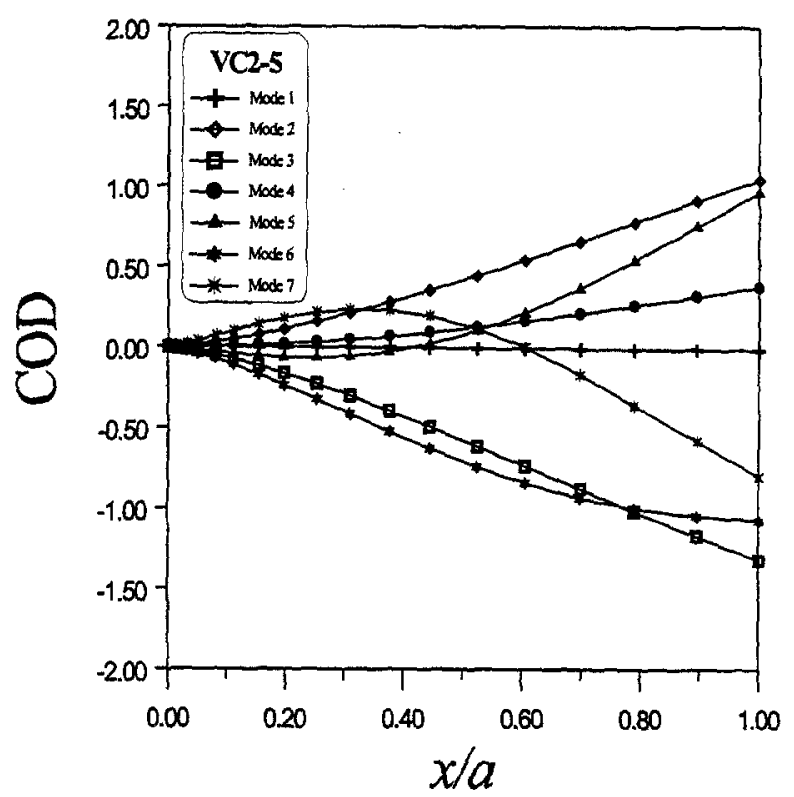

(b)

Fig. 11-(a) Normalized displacement $\left(w / w_{\max }\right)$ and (b) crack-opening displacement (COD) values of the crack faces for the VC2-5 plate

opening displacement (i.e., modes $1,3,4$ and 7 for the VC1-2 plate; modes 1, 3, 5 and 7 for the VC1-5 plate; and mode 1 for the VC2-2 plate). For these cases, the stress intensity factor will be zero, implying that the crack will not propagate at these resonant frequencies. The out-of-plane motion of a vibrating cracked plate is investigated in this study, and the effect of the contact of crack faces is neglected. However, if the in-plane vibration of the cracked plate is studied, then this crack contact effect will be of considerable importance and should be taken into account in the analysis of a vibrating plate with cracks. 


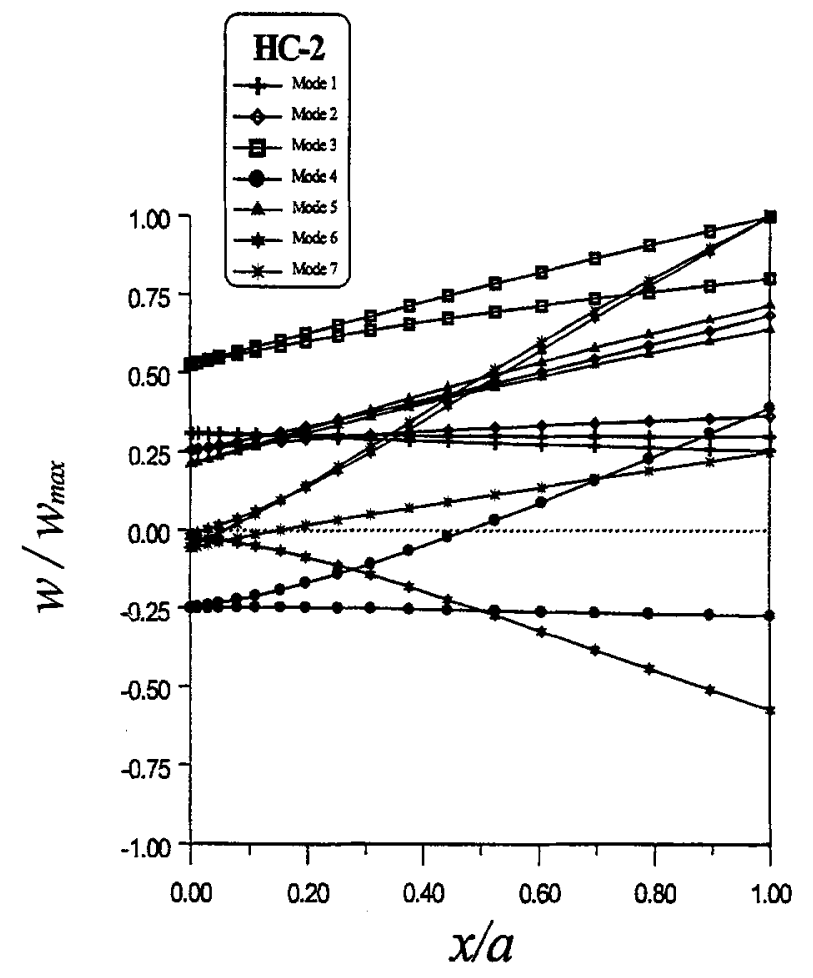

(a)

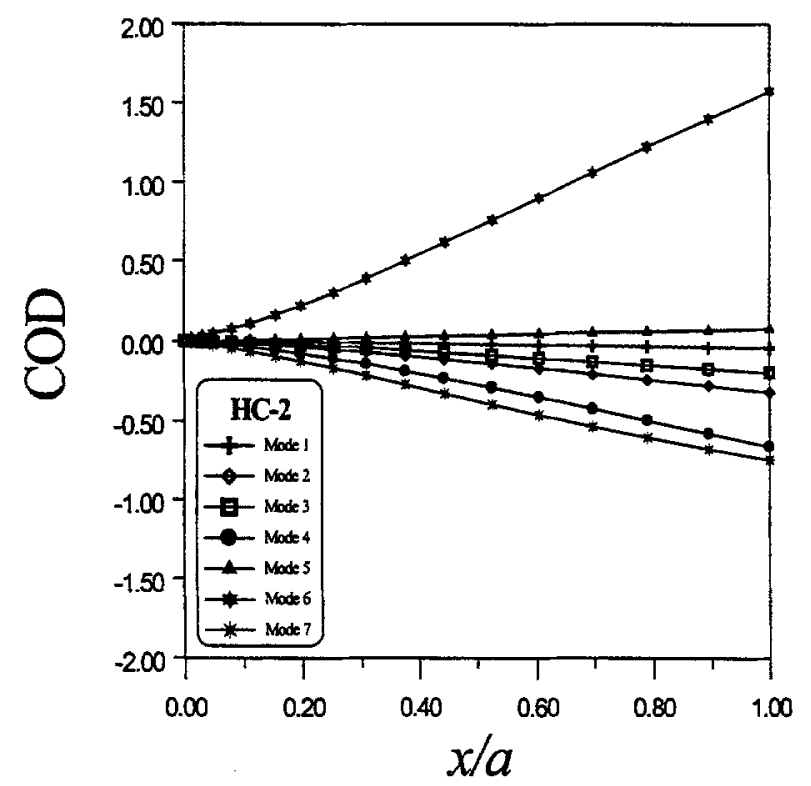

(b)

Fig. 12-(a) Normalized displacement $\left(w / w_{\max }\right)$ and (b) crack-opening displacement (COD) values of the crack faces for the HC-2 plate

\section{Acknowledgments}

The authors thank the National Science Council of the Republic of China for supporting this research under Grant No. NSC 87-2218-E002-022.

\section{References}

1. Rastogi, P.K., Holographic Interferometry, Springer-Verlag Berlin, Germany (1994).

2. Butters, J.N. and Leendertz, J.A., "Speckle Pattern and Holographic Techniques in Engineering Metrology," Opt. Laser Tech., 3, 26-30 (1971).

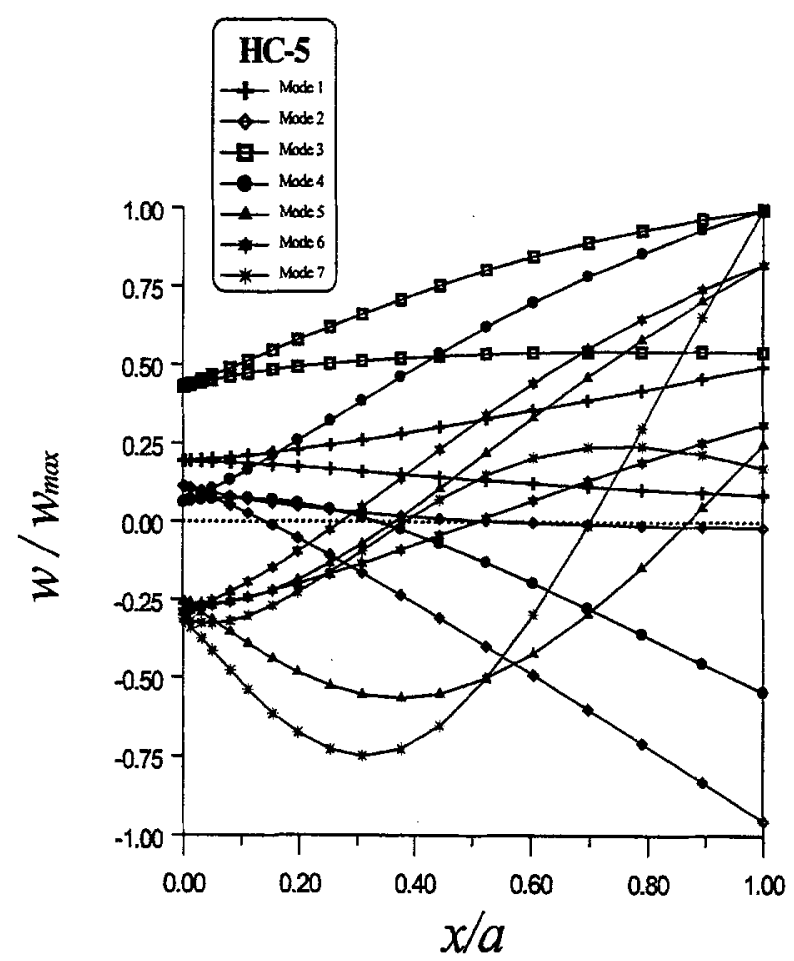

(a)

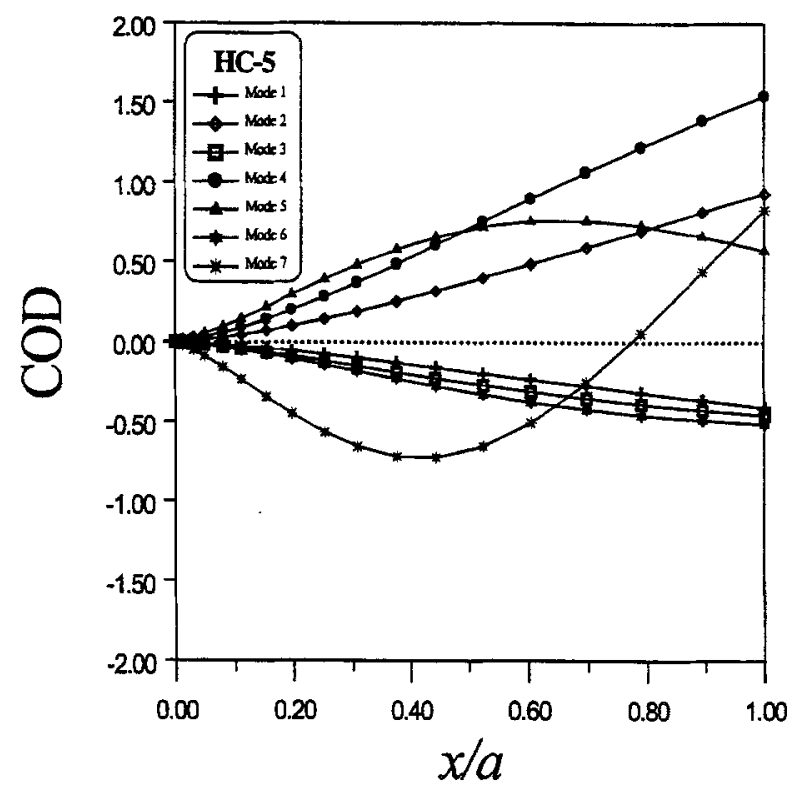

(b)

Fig. 13-(a) Normalized displacement $\left(w / w_{\max }\right)$ and (b) crack-opening displacement (COD) values of the crack faces for the $\mathrm{HC}-5$ plate

3. Cloud, G.L., Optical Methods of Engineering Analysis, Cambridge University Press, Cambridge (1998).

4. L $\phi \mathrm{kberg}, O . J$. and Hogmoen, $K$., "Use of Modulated Reference Wave in Electronic Speckle Pattern Intefferometry," J. Phys. E: Sci. Instr., 9, 847851 (1976).

5. Creath, K. and Slettemoen, G.A., "Vibration-observation Techniques for Digital Speckle-pattern Interferometry," J. Opt. Soc. Am. A, 2, 16291636 (1985).

6. Pouet, B., Chatters, T., and Krishnaswamy, S., "Synchronized Reference Updating Technique for Electronic Speckle Interferometry," J. Nondestr. Eval., 12, 133-138 (1993). 
7. Wang, W.C., Hwang, C.H., and Lin, S.Y., "Vibration Measurement by the Time-averaged Electronic Speckle Pattern Interferometry Methods," Appl. Opt., 35, 4502-4509 (1996).

8. Ma, C.C. and Huang, C.H., "The Investigation of Three-dimensional Vibration for Piezoelectric Rectangular Parallelepipeds by Using the AFESPI Method," IEEE Trans. Ultrasonics, Ferroelectrics, and Frequency Control 48 (2001).

9. Huang, C.H. and Ma, C.C., "Vibration Characteristics for Piezoelectric Cylinders Using Amplitude-fuctuation Electronic Speckle Pattern Interferometry;" AIAA J., 36, 2262-2268 (1998).

10. Leissa, A.W., "Vibration of Plates," NASA SP-160 (1969).

11. Lynn, P.P. and Kumbasar, N., "Free Vibration of Thin Rectangular Plates Having Narrow Cracks with Simply Supported Edges," Develop. Mech., 4, 911-928 (1967).

12. Stahl, B. and Keer, L.M., "Vibration and Stability of Cracked Rectangular Plates," Int. J. Solids Struct., 8, 69-91 (1972).

13. Hirano, $Y$, and Okazaki, $K$., "Vibration of Cracked Rectangular Plates," Bull. JSME, 23, 732-740 (1980).

14. Solecki, $R$., "Bending Vibration of a Simply Supported Rectangular Plate with a Crack Parallel to One Edge," Eng. Fract. Mech., 18, 1111-1118 (1983).
15. Qian, G.L., Gu, S.N., and Jiang, J.S., "A Finite Element Method of Cracked Plates and Application to Vibration Problems," Computers Struct., 39, 483-487 (1991).

16. Krawczuk, $M$., "Natural Vibrations of Rectangular Plates with $a$ Through Crack," Arch. Appl. Mech., 63, 491-504 (1993).

17. Lee, H.P. and Lim, S.P., "Vibration of Cracked Rectangular Plates Including Transverse Shear Deformation and Rotary Inertia," Computers Struct., 49, 715-718 (1993).

18. Maruyama, K. and Ichinomiya, $O$., "Experimental Study of Free Vibration of Clamped Rectangular Plates with Straight Narrow Slits," JSME Int. J. Ser. III, 32, 187-193 (1989).

19. Cawley, P. and Adams, R.D., "The Location of Defects in Structures from Measurements of Natural Frequencies," J. Strain Anal., 14 (2), 49-57 (1979).

20. Gudmundson, P., "The Dynamic Behaviour of Slender Structures with Cross-sectional Cracks," J. Mech. Phys. Solids, 31, 329-345 (1983).

21. Cawley, P. and Ray, R.A., "Comparison of the Natural Frequency Changes Produced by Cracks and Slots," ASME J. Vibrat., Acoust., Stress, Reliab. Des., 110, 366-370 (1988).

22. Hibbit, Karlsson and Sorensen, Manuals for ABAQUS 5.5, Hibbit, Karlsson and Sorensen, Pawtucket, RI (1995). 